\title{
O CONTROLE DE PROCESSOS EM ÁREAS URBANAS COM O USO DA VEGETAÇÃO
}

Generoso De Angelis Neto ${ }^{1}$, Bruno Luiz Domingos De Angelis ${ }^{2}$, Izabel Cristina Scalabrin Dall'Agnol $^{3}$, Wagner Luiz Kreling ${ }^{4}$

\section{RESUMO}

Será apresentada nesse trabalho uma análise de como a vegetação, com ênfase para as espécies arbóreas, pode ser utilizada na prevenção do desencadeamento de processos em áreas urbanas. Serão discutidos alguns destes processos do meio físico, em especial aqueles de maior ocorrência nestas áreas, e suas interações com a presença de atividades antrópicas ou processos tecnológicos.

Palavras-chave: análise de vegetação, prevenção, processos, áreas urbanas.

\section{THE PROCESSES CONTROL IN URBAN AREAS USING VEGETATION}

\begin{abstract}
This work shows an analysis of how vegetation, with emphasis on arboreal species, can be used to prevent the processes unleashment in urban areas. Some of these physics processes are going to be discussed, in special those more ocurrent on these places and its interactions with human activities presence or technological processes.
\end{abstract}

Key-words: Vegetation analysis, prevention, processes, urban areas.

\footnotetext{
1 Engenheiro Civil, Professor Universitário, Universidade Estadual de Maringá, Maringá, Paraná, ganeto@uem.br.

Engenheiro Agrônomo, Professor Universitário, Universidade Estadual de Maringá, Maringá, Paraná, bldangelis@uem.br.

${ }^{3}$ Geógrafa, Realeza, Paraná.

${ }^{4}$ Geógrafo, Londrina, Paraná.
} 


\section{INTRODUÇÃO}

O ser humano ocupa o planeta Terra há milhares de anos e conseguiu manter um certo equilíbrio nas relações de troca entre o homem e o ambiente, por muito tempo. Com o aumento da população humana e o desenvolvimento de novas tecnologias, passou-se a uma maior apropriação do meio, conseguindo habitar em todas as regiões do planeta, alterando o ambiente natural (FORNASARI FILHO, 1995). O uso e ocupação pouco criteriosa do solo originam alguns problemas de considerável gravidade. Tal situação se agrava de modo crescente, na medida em que se aceleram os processos de urbanização, que geralmente se dá mais sob a influência de razões de marcado que pelas reais potencialidades das áreas a serem ocupadas. Isso acaba determinando o parcelamento de regiões e locais extremamente problemáticos, como por exemplo, as áreas de relevos mais íngremes e as áreas de várzeas sujeitas a inundação (ANGELIS NETO, 1999). Assim, para que se consiga prevenir o desencadeamento de processos do meio físico causados por atividades antrópicas, e os impactos ambientais daí decorrentes, passa-se a caracterizar tanto estas atividades quanto os processos do meio físico selecionados, para então demonstrar-se o uso da vegetação no controle de seu desenvolvimento.

\section{ATIVIDADES ANTRÓPICAS}

Entende-se aqui como atividade antrópica ou modificadora do meio ambiente, toda atividade humana (obra civil, atividade agrícola ou de mineração e outras formas de uso e ocupação do solo) que altera processos, propriedades ou características físicas, químicas ou biológicas, ou interferem em usos preexistentes de um determinado ambiente (FORNASARI FILHO et al., 1992).

A Resolução 01/86 do CONAMA especifica algumas atividades antrópicas que são potenciais causadoras de alterações no meio ambiente, sendo, por isso, alvo obrigatório do EIA e respectivo Rima. Algumas destas atividades são de ocorrência maior em áreas urbanas, outras em áreas rurais e outras até em escalas regionais ou nacionais. MOREIRA (1993) também apresenta uma série destas atividades, destacando a necessidade de se estabelecer a classificação por porte, potencial de impacto, tipo de atividade e localização, como ilustra o quadro 1. Numa análise ambiental á necessário prever as alterações que os processos do meio físico podem sofrer ao ocorrer a intervenção de um processo tecnológico de uma dada atividade. As alterações em um processo do meio físico, juntamente com as de ordem biológica e sócio-econômica, correspondem às alterações do próprio meio ambiente, ou seja, às degradações ambientais. 
Quadro 1 - Atividades modificadoras do meio ambiente

\begin{tabular}{|c|c|c|}
\hline \multicolumn{3}{|c|}{ ATIVIDADES ANTRÓPICAS MODIFICADCRAS } \\
\hline 1. CBRAS DE SAMEAMEITTO & 2. URBAN【ZAÇÃO & $\begin{array}{l}\text { 3. TRANSPCRTE E } \\
\text { TRANSMISSÄO }\end{array}$ \\
\hline $\begin{array}{c}\text { Sistemas de ab astecimento de água } \\
\text { Sistemas de esgotamento sanitário } \\
\text { Sistemas de drenagem } \\
\text { Estações de tratamento de água } \\
\text { Estações de tratamento de esgotos } \\
\text { Adutoras } \\
\text { Troncos coletores de esgotos } \\
\text { Emissários } \\
\text { Barragens de captação e re servação } \\
\text { Dragagem de corpos d'água } \\
\text { Retificação de rios } \\
\text { Aterros sanitários } \\
\text { Aterros de resíduos industriais } \\
\text { Incineradores } \\
\text { Usinas de compostagem } \\
\text { Garagens de empresas de lixo } \\
\text { urbano }\end{array}$ & $\begin{array}{c}\text { Pólos industriais } \\
\text { Distritos industriais } \\
\text { Pólos turísticos } \\
\text { Loteamentos } \\
\text { Condomínios } \\
\text { Desmembramentos } \\
\text { Aterros aterros } \\
\text { hidráulicos } \\
\text { Obras de contenção de } \\
\text { encostas } \\
\text { Conjuntos habitadionais } \\
\text { Hotéis } \\
\text { dubes } \\
\text { Camping } \\
\text { Marinas } \\
\text { Piers e cais } \\
\text { Residências }\end{array}$ & $\begin{array}{c}\text { Rodovias } \\
\text { Ferrovias } \\
\text { Hidrovias } \\
\text { Matropolitanos } \\
\text { Ferrovias urtanas } \\
\text { Cleodutos } \\
\text { Gasodutos } \\
\text { Minerodutos } \\
\text { Linhas de transmissão } \\
\text { Torres de transmissão } \\
\text { Estações de transmissão } \\
\text { de energia elética }\end{array}$ \\
\hline 4. EXTRAÇÃO MLINERAL & 5. AGROPEQÚRIA & $\begin{array}{l}\text { 6. COMÉRCIOE } \\
\text { SERVICOS }\end{array}$ \\
\hline $\begin{array}{c}\text { Areia } \\
\text { Argila, saibro } \\
\text { Pedreiras de brita } \\
\text { Pedreiras de blocos } \\
\text { Carvão mineral } \\
\text { Chumbo } \\
\text { Turfa } \\
\text { Calcário } \\
\text { Petróleo e gás natural } \\
\text { Amianto } \\
\text { Xisto } \\
\text { Cutros mineraise minérios }\end{array}$ & $\begin{array}{c}\text { Obras de irrigação e } \\
\text { drenagem } \\
\text { Reflorestamento } \\
\text { econômico } \\
\text { Extração de madeira e } \\
\text { carvão vegetal } \\
\text { Plantações extensivas } \\
\text { Oriação de animais } \\
\text { Parcelamentos agrícolas } \\
\text { Aquicultura }\end{array}$ & $\begin{array}{c}\text { Hospitais } \\
\text { Supermercados } \\
\text { Centros comerciais } \\
\text { Cemitérios } \\
\text { Lavanderias } \\
\text { Armazenagem de } \\
\text { produtos tóxicose } \\
\text { perigosos }\end{array}$ \\
\hline $\begin{array}{c}\text { 7. USINAS DE GERAC,ÃO DE } \\
\text { ENERGIA }\end{array}$ & $\begin{array}{l}\text { 8. INSTALACOÕES } \\
\text { TERMLINAIS }\end{array}$ & $\begin{array}{l}\text { 9. INDÚSTRIAS DE } \\
\text { TRANISFORMACÃOA }\end{array}$ \\
\hline $\begin{array}{l}\text { Hidrelétricas } \\
\text { Termoelétricas } \\
\text { Teımonucle ares }\end{array}$ & $\begin{array}{c}\text { Portos } \\
\text { Aeroportos } \\
\text { Terminais de minério } \\
\text { Terminais de petróleo e } \\
\text { derivados } \\
\text { Helipontos } \\
\text { Garagens } \\
\text { Terminais rodoviários }\end{array}$ & Todos os gêneros \\
\hline
\end{tabular}

Fonte: MOREIRA (1993).

\section{PROCESSOS DO MEIO FÍSICO}

As alterações do meio físico referem-se basicamente às ações que ocorrem sobre este meio e seus processos. Entende-se por meio físico ao conjunto do ambiente caracterizado pela interação de componentes predominantemente abióticos, quais sejam, materiais terrestres (solos, rochas, água e ar) e tipos naturais de energia (gravitacional, solar, energia interna da Terra e outras), incluindo suas modificações decorrentes da ação biológica e humana (FORNASARI FILHO et al., 1992). Neste contexto, as informações obtidas sobre o meio físico são de fundamental importância de maneira que o equilíbrio entre seus componentes seja mantido dentro de limites satisfatórios. 
Uma obra ou qualquer outra forma de uso do solo num determinado ambiente, ainda que garantida com seus próprios fatores de estabilidade e segurança, pode não manter uma relação equilibrada com o meio circundante. Por exemplo, a drenagem de uma estrada pode ter sido adequadamente projetada para captar e eliminar as águas da pista e, portanto, garantir sua estabilidade e segurança ao tráfego, mas o lançamento concentrado das águas captadas poderá provocar alterações significativas no escoamento superficial dos terrenos e, conseqüentemente, acelerar os processos erosivos (OLIVEIRA et al., 1995).

São diversos os métodos e os níveis de aprofundamento que podem conduzir à caracterização isolada de um ou outro processo do meio físico, e dependem das técnicas e objetivos dos diferentes ramos de estudo, seus variados campos de atuação na atmosfera, hidrosfera e litosfera ou biosfera. Os processos do meio físico a serem abordados neste estudo são: erosão, assoreamento, escorregamento e subsidência.

\section{O VERDE E SEUS USOS NO CONTROLE DE PROCESSOS}

De acordo com o que fora expresso em relação aos processos tecnológicos e/ou atividades antrópicas e aos do meio físico selecionados, tem-se agora as influências da vegetação sobre o controle do desenvolvimento de impactos ambientais, de acordo com o contido no quadro 2.

Constata-se deste quadro que para as funções da vegetação selecionadas (8), 53\% são muito importante, $19 \%$ importantes, $13 \%$ pouco importantes e apenas 15\% são sem importância para o controle do desenvolvimento dos processos do meio físico analisados. Com relação aos processos tecnológicos, 63\% são muito importantes, 13\% são importantes, 17\% são pouco importantes e 7\% são sem importância. 
Quadro 2 - Funções da vegetação e sua influência sobre os processos tecnológicos e do meio físico selecionados

\begin{tabular}{|c|c|c|c|c|c|c|c|c|c|c|c|c|c|}
\hline VEGETAÇĀO & & $\begin{array}{l}\text { POC } \\
\text { Fis }\end{array}$ & $\begin{array}{l}\text { ESSC } \\
\text { AEIC } \\
\text { ICO }\end{array}$ & & & OC & ESSC & as $\mathrm{T}$ & ECN & OLÓC & GICC & & \\
\hline FUNÇŌES & 1 & 2 & 3 & 4 & 5 & 6 & 7 & 8 & 9 & 10 & 11 & 12 & 13 \\
\hline $\begin{array}{c}\text { 1- Estabilização de determinada } \\
\text { superfíce pela fixação do solo } \\
\text { pelas raizes das plantas }\end{array}$ & $\bullet$ & $\bullet$ & - & $\mathbf{\square}$ & - & $\bullet$ & • & $\bullet$ & - & 0 & 0 & 0 & $\bullet$ \\
\hline $\begin{array}{c}2 \text { - Obstáculo contra o vento e } \\
\text { ruídos }\end{array}$ & 0 & $\overline{\mathbf{a}}$ & $\square$ & $\square$ & $\bullet$ & $\bullet$ & $\bullet$ & $\bullet$ & 0 & $\mathbf{\square}$ & 0 & $\bullet$ & $\bullet$ \\
\hline $\begin{array}{l}3 \text { - Proteção da qualidade da } \\
\text { água, impedindo que os poluentes } \\
\text { escoem para os aursos d'água }\end{array}$ & $\bullet$ & $\bullet$ & $\mathbf{\square}$ & - & - & $\bullet$ & - & $\bullet$ & - & $\bullet$ & $\bullet$ & $\bullet$ & - \\
\hline $\begin{array}{l}4 \text { - Filtragem e equilibrio do } \\
\text { índice de umidade do ar; } \\
\text { diminuindo a poeira e a poluição, } \\
\text { refrescando a atmo sfera }\end{array}$ & 0 & $\square$ & $\square$ & $\square$ & - & $\bullet$ & a & 口 & 0 & $\mathbf{\square}$ & $\mathbf{\square}$ & 0 & • \\
\hline $\begin{array}{l}5 \text { - Proteção às nascentes e } \\
\text { mananciais }\end{array}$ & 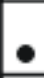 & 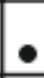 & - & $\bullet$ & $\bullet$ & $\bullet$ & - & $\bullet$ & ? & $\mathbf{a}$ & 口 & - & - \\
\hline $\begin{array}{l}\text { 6- Aumento da taxa de } \\
\text { infilttação das águas pluviais }\end{array}$ & $\bullet$ & ? & - & - & $\mathbf{0}$ & $\bullet$ & 0 & 0 & 0 & $\square$ & $\square$ & $\square$ & 0 \\
\hline $\begin{array}{l}7 \text { - Interação entre as atividades } \\
\text { humanas e o meio ambiente }\end{array}$ & $\bullet$ & $\bullet$ & 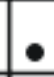 & 口 & 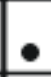 & $\bullet$ & - & • & 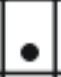 & - & 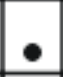 & $\bullet$ & - \\
\hline $\begin{array}{l}8 \text { - mantém as propriedades do } \\
\text { solo: permeabilidade e fertilidade }\end{array}$ & & 0 & & 0 & 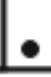 & $\bullet$ & 0 & $\square$ & 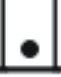 & $\square$ & $\square$ & $\square$ & - \\
\hline
\end{tabular}

\section{CONCLUSÕES}

A utilização do verde, principalmente as espécies arbóreas, no controle e prevenção do desencadeamento de processos do meio físico, está bastante relacionado com os mesmos, com o grau de importância variável em até $85 \%$ dos casos. Percebe-se que as espécies vegetais podem ser usadas também na recuperação de áreas degradadas por estes processos, através da sua utilização paisagística, como elemento estabilizador do processo ou como barreira física à ocorrência e desenvolvimento destes. Aliando-se suas funções físicas e mecânicas consegue-se não só recuperar estas áreas degradadas como também torná-las aptas para outras formas de usos e funções.

Com relação aos processos tecnológicos/atividades antrópicas analisadas, esta importância aumenta para 93\%, o que configura um estreito relacionamento que o verde tem com a prevenção e controle de impactos ambientais ocasionados por estes processos.

Dessa forma, percebe-se que a vegetação pode ser utilizada para:

- Restauração: associada à idéia de reprodução das condições exatas do local, tais como eram antes de serem alteradas pela intervenção; 
- Recuperação: associada à idéia de que o local alterado seja trabalhado de modo a que as condições ambientais se situem próximas às condições anteriores à intervenção, ou seja, trata-se de devolver ao local o equilíbrio e a estabilidade dos processos ambientais ali atuantes anteriormente;

- Reabilitação: associada à idéia de que o local alterado deverá ser destinado a uma dada forma de uso do solo, de acordo com projeto prévio e em condições compatíveis com a ocupação circunvizinha, ou seja, trata-se de reaproveitar a área para outra finalidade.

\section{REFERÊNCIAS BIBLIOGRÁFICAS}

ANGELIS NETO, G. As deficiências nos instrumentos de gestão e os impactos ambientais causados por resíduos sólidos urbanos: O caso de Maringá/PR. São Paulo, 1999. Tese (Doutorado) - Escola Politécnica da Universidade de São Paulo

CONSELHO NACIONAL DO MEIO AMBIENTE (CONAMA). Resoluções do CONAMA: 1984/86. Brasília, SEMA, 1986.

FORNASARI FILHO, N. Alterações nos processos do meio físico por mineração: Estudo de casos de instrumentos de gerenciamento ambiental. São Paulo, 1995. Dissertação (Mestrado) - Programa de Pós-graduação em Ciência Ambiental, Universidade de São Paulo.

FORNASARI FILHO, N. (coord.) et al. Alterações do meio físico decorrentes de obras de engenharia. São Paulo, Instituto de Pesquisas Tecnológicas, 1992. (Publicação IPT; n. 1.972).

MOREIRA, I.V.D. Aplicações da avaliação de impactos ambientais: Critérios para seleção de projetos. In: JUCHEM, P.A. (coord.) Manual de avaliação de impactos ambientais. $2^{\mathrm{a}}$ edição, Curitiba, IAP/GTZ, 1993.

OLIVEIRA, A.M.S. Geologia aplicada a la sedimentacion. In: CAVALCANTI, R.N. (coord.) et al. Aspectos geológicos de proteccion ambiental. Montevideo, ORCYT/UNESCO, 1995. 